system is speedier and more flexible, but it is ultimately limited by the former. The emergence of large brains in human evolution is credited to neoteny, that is, the retention of juvenile traits whereby the brain goes on growing in size after the growth of the rest of the body has slowed or ceased.

Having laid the structural groundwork, Bonner turns to the most basic behaviours. A long chapter on animal societies (which draws heavily on Wilson's Sociobiology) relies on the premise that culture requires communication, which is most developed in social organisms. Here, and throughout the book, Bonner chooses to start with microorganisms and work his way through progressively more complex multicellular forms. An excellent discussion of genetic flexibility is followed by the introduction of the concept of a dichotomy of behavioural flexibility: single-response behaviour versus multiple-choice behaviour; this appears to be "nature versus nurture" re-labelled.

The real problems begin to arise with the author's treatment of learning and teaching. All social learning seems to be classified as imitation, with no distinction being made between types requiring differing degrees of mental ability mynah birds and human infants may both learn English, but the learning of the bird is merely mindless mimicry. No mention is made of "mixed" forms, for example observational learning by a combination of stimulus enhancement (social) and trialand-error learning (non-social). Finally, there is no reference to behaviours which involve communication but not (necessarily) learning, social facilitation of pecking in domestic chicks, for example. Crucial to the author's argument is teaching, which he defines as "... the release of sets of signals specifically designed to alter the behaviour of another individual"'. This presents a rare example of ambiguity: in a general sense such a definition applies to all communication; in a more specific sense, it leaves open the question of whether or not intentionality (or goal-directedness) is involved. The reader is told that a large share of teaching by higher vertebrates can be considered as parental guidance, and that a parent will shape its offspring's imitative performance with nudges, pokes and slaps. But, apart from a single anecdote, no evidence of this sort of behaviour is presented. Contrary to the author's conclusion, it seems likely that it is just this sort of teaching which is conspicuously absent in non-human animals.

The book builds toward a synthetic final chapter which I found somewhat bewildering. Norton-Griffiths's exemplary work on the intergenerational transmission of feeding techniques in oyster-catchers is given suitable credit, but a number of other, equally significant studies are not mentioned. The "natural experimental" research into cultural innovation and diffusion in Japanese monkeys rates only one paragraph; an admittedly fascinating anecdote of one-trial, avoidance learning by elephants is given preference to the many studies of culture in non-human primates - Menzel's volume on the subject is ignored; fidelity to nesting sites in migratory birds is emphasized, in spite of the fact that no social learning need be posited, just as it is not invoked to explain the homing of Pacific salmon to spawn; even the memorable example of milkbottle opening by tits merits only three sentences. Finally, the section on human culture cites no specific examples, and some of its general conclusions will cause disquiet amongst the social scientist for whom the book is intended; for example, the author's linking of the rise of culture to the rise of writing seemingly bars extant pre-literate societies from consideration.

Yet, overall, in this book Bonner has produced a clear, compelling and wideranging account of the bases for social communication in animals. However, those more interested in the evolutionary mechanisms of transition from non-human to human culture are left wanting. That particular book remains to be written.

W.C. McGrew is a Lecturer in Psychology at the University of Stirling and a Visiting Faculty Member at the University of North Carolina at Charlotte.

His publishers describe him as "a passionate observer of nature", and this is what emerges from his prose. He gives us accurate and percipient accounts of the plants, insects, mammals and particularly the birds seen in his garden and in the Hampshire countryside. Some scientists may find his description of his feelings, and his attribution of human emotions to birds and even insects, alien to their tastes, but they will soon be brought back to earth by his unsentimental and accurate accounts of life and death in the countryside.

Hudson's love of rural life was mirrored by his hatred for urban living. He disliked

\section{SCIENTIFIC BOOKSHOP}

H.K. LEWIS can supply works in all branches of Pure and Applied Science. Catalogues on request. Please state interests.

\section{SCIENTIFIC LENDING LIBRARY}

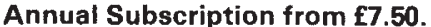

(Available in U.K. only)

Reduced rates for multiple subscriptions.

\section{Prospectus post free on request.}

Quarterly List of New Books and new editions added to the Library sent post free to subscribers regularly.

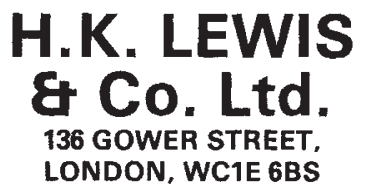

Telephone: 01-387 4282

Telegrams: "Publicavit,

London, WCIE 6BS."

Circle No. 23 on Reader Enquiry Card.

the townsmen, with "their pale civilized faces - they are out of my world - the real world". His passion was for "wildness the rude heath, the beautiful desolation; furze and ling and bramble and bracken to grow on me, and only wild creatures for visitors and company". He was of course aware that he was observing not the natural face of England, but the result of the interplay of human activities and ecological processes. He describes prehistoric barrows as well as traditional farmhouse and agricultural activities. But at the time he was writing it was possible to imagine that there was a harmony between man and nature which resulted in the beautiful landscape he so vividly describes.

How he would have hated the changes which have taken place in his beloved Hampshire in recent years. Many of the woods and heaths have gone, some of the hedges have been ripped out. Men are even prospecting for oil! Modern farming is very different from that of his day. Yet a great deal remains. We can, if we are lucky, still see most of the sights he so graphically describes. But few of us have his "seeing eye", and in a lifetime of study may not make all the observations his skill and his sympathy made possible in a few brief years at the beginning of this century.

Kenneth Mellanby is an editor of Collins' New Naturalist series, which is concerned with wildlife in Britain. His Farming and Wildlife, in this series, will appear in 1981. was, in South America or rural England. 